\title{
Recurrent infections in homozygous sickle cell disease
}

\author{
Stephen A Magnus, Ian R Hambleton, Faridah Moosdeen, Graham R Serjeant
}

\begin{abstract}
The characteristics of 214 episodes of invasive bacterial infection among 176 patients with homozygous sickle cell (SS) disease were examined. Streptococcus pneumoniae occurred in 81 episodes, Salmonella spp in 70, Haemophilus influenzae type b in 30, Escherichia coli in 24, and Klebsiella spp in nine. The cumulative incidence showed that $S$ pneumoniae and $H$ influenzae occurred predominantly before 5 years of age and were uncommon thereafter, Salmonella spp increased almost linearly with age, and Klebsiella spp and $E$ coli predominated in patients over 10 years of age. Escherichia coli had a different epidemiology-it was found in older children, almost entirely girls. Excluding this organism from an analysis of recurrent bacterial infections, the standardised incidence rates for second and third infections were 4.8 and 15.8 times greater, respectively, than the SS population average. This implies that the susceptibility to infection is characteristic of a subgroup of patients with SS disease and that sick patients with previous bacteraemia should be investigated early and aggressively for further infection.
\end{abstract}

(Arch Dis Child 1999;80:537-541)

Keywords: sickle cell; bacteraemia; infection; Streptococcus pneumoniae

Patients with homozygous sickle cell (SS) disease are at increased risk of infection with Streptococcus pneumoniae, Haemophilus influenzae type b, Salmonella spp, Escherichia coli and Klebsiella spp. ${ }^{1-3}$ Several mechanisms are believed to contribute to this susceptibility, a major factor being the early loss of splenic function, which may be abnormal as early as the 1 st year of life. ${ }^{4}$ Development of clinical splenomegaly in the first 6 months of life has been shown to be significantly associated with greater risk of subsequent pneumococcal septicaemia. ${ }^{5}$ This susceptibility is assumed to be characteristic of the SS genotype as a whole but because splenic function is lost at different rates in different patients, it might be expected that a subgroup of patients would be particularly susceptible to infection and would perhaps develop recurrent infections. We tested this hypothesis in a retrospective study of Jamaican patients with SS disease.

\section{Patients and methods}

PATIENTS

The patients attended the sickle cell clinic of the University Hospital of the West Indies,
Kingston, Jamaica. All had SS disease diagnosed by standard criteria ${ }^{6}$ and came from two clinic populations. The cohort group included all patients with SS disease detected during the screening of 100000 consecutive, nonoperative deliveries at the main Government Maternity Hospital (Victoria Jubilee) between June 1973 and December 1981, and these were clinically followed from birth. The main group included all other patients, most of whom had been symptomatically referred, although this symptomatic bias has been reduced by long term follow up of the steady state. To reduce the symptomatic bias in this second group, patients were required to have had at least two clinic visits and not to have been referred initially to the clinic with bacterial infection. Our study was confined to infections caused by $S$ pneumoniae, $H$ influenzae type b, Salmonella spp, E coli, or Klebsiella spp between 1 January 1974 and 31 December 1997.

There were 3820 patients (including 311 cohort patients) with 218 episodes of infection among 180 patients (90 episodes among 64 cohort patients). Four episodes identified on initial clinic referral in main group patients were excluded, leaving 214 eligible episodes among 176 patients. Differences in recruitment of the cohort and main groups resulted in significantly different age structures. The median age at last clinic visit was 17.8 years (interquartile range, 11.2-21.2; total range, $0.1-24.5)$ for the cohort and 20.7 years (10.7$31.4 ; 0.1-80.6$ ) for the main group (MannWhitney $\mathrm{U}$ test, $\mathrm{z}=7.5 ; \mathrm{p}<0.001$ ).

\section{METHODS}

In the sickle cell clinic, infections receive specific computer codings prospectively and all dockets with such codings were reviewed and cross checked by examination of the records in the department of microbiology laboratory. In the cohort study, complete data were available from birth.

\section{DEFINITIONS}

We defined invasive bacterial infections as the isolation of one of the five organisms from cultures of blood or cerebral spinal fluid and, in the case of Salmonella spp, from sinuses or aspiration from bone sites. Patients with recurrent isolations of $S$ pneumoniae were assumed to have separate infections if the serotype differed, or if the same serotype was isolated after an arbitrary intervals of 14 days.

\section{STATISTICAL METHODS}

Age distributions at last visit for cohort and main patients exhibited non-normality and so were summarised by median, interquartile 
Table 1 Distribution of infections by age, sex, patient group, and organism

\begin{tabular}{|c|c|c|c|c|c|c|c|c|c|c|c|c|c|}
\hline & \multicolumn{6}{|c|}{ Main group (age (years)) } & \multicolumn{6}{|c|}{ Cohort group (age (years)) } & \multirow[b]{2}{*}{ Grand total } \\
\hline & $0-2$ & $3-5$ & $6-9$ & $10-19$ & $20+$ & Total & $0-2$ & $3-5$ & $6-9$ & $10-19$ & $20+$ & Total & \\
\hline \multicolumn{14}{|l|}{ Bacterial isolate } \\
\hline Streptococcus pneumoniae & $7 / 4$ & $5 / 10$ & $2 / 6$ & $2 / 2$ & $1 / 3$ & $17 / 25$ & $6 / 9$ & $8 / 7$ & $5 / 0$ & $1 / 1$ & $1 / 1$ & $20 / 18$ & $81(38 \%)$ \\
\hline Salmonella spp & $6 / 1$ & $1 / 2$ & $10 / 2$ & $1 / 7$ & $10 / 3$ & $28 / 15$ & $3 / 3$ & $4 / 1$ & $7 / 5$ & $2 / 2$ & $0 / 0$ & $16 / 11$ & $70(33 \%)$ \\
\hline Haemophilus influenzae & $3 / 2$ & $7 / 1$ & $1 / 0$ & $1 / 0$ & $1 / 1$ & $13 / 4$ & $8 / 2$ & $1 / 1$ & $0 / 1$ & $0 / 0$ & $0 / 0$ & $9 / 4$ & $30(14 \%)$ \\
\hline Escherichia coli & $0 / 0$ & $0 / 1$ & $0 / 0$ & $0 / 0$ & $0 / 17$ & $0 / 18$ & $1 / 0$ & $0 / 0$ & $0 / 0$ & $0 / 3$ & $0 / 2$ & $1 / 5$ & $24(11 \%)$ \\
\hline Klebsiella spp & $1 / 0$ & $0 / 0$ & $0 / 0$ & $1 / 0$ & $2 / 0$ & $4 / 0$ & $0 / 0$ & $0 / 0$ & $1 / 0$ & $2 / 1$ & $0 / 1$ & $3 / 2$ & $9(4 \%)$ \\
\hline Total (\%) & $24(11)$ & $27(13)$ & $21(10)$ & $14(7)$ & $38(18)$ & 124 & $32(15)$ & $22(10)$ & $19(9)$ & $12(6)$ & $5(2)$ & 90 & 214 \\
\hline
\end{tabular}

Results are number of male patients/female patients.

range, and total range and differences compared by the Mann-Whitney U test. Sex composition was assessed using the $\chi^{2}$ test.

Incidence rates for cohort and main groups by organism, age, and sex were estimated as the ratio of the number of events divided by the number of person-years of exposure. Confidence intervals $(95 \% \mathrm{CI})$ for the incidence rates were calculated using jackknife methodology ${ }^{7}$ to compensate for multiple events within patients. Incidence rates were compared using rate ratios, controlling for confounding factors by stratification and subsequent pooling to give the Mantel-Haenszel estimate of the rate ratio. Standardised infection rates were calculated by comparing the infection rate of any subgroup (age, sex, organism) with the appropriate complete sample (cohort, main, or both) reference rate, a technique known as indirect standardisation. Potential disadvantages of age stratified rates are the need for arbitrary breakpoints and the use of narrow bands, which may cause unstable estimates. An alternative procedure plotted the cumulative rate $^{8}$ against time divided into short bands. This cumulative rate was compared informally across infection groups.

The risk of recurrent infections was assessed by assuming the hypothesis that episodes of infection were independent events within individuals. Disproving this hypothesis would imply that individual patients were more or less prone to recurrent infection. Incidence rates, standardised infection rates, and risk ratios for first, second, and third episodes were calcu- lated and compared as described. Significance was assumed at the 5\% level. All analyses were performed using Stata statistical software (Release 5.0; Stata Corporation, College Station, Texas, USA).

\section{Results}

There were 214 bacteraemias, $S$ pneumoniae occurring in 81 (37.9\%), Salmonella spp in 70 $(32.7 \%), H$ influenzae in $30(14.0 \%), E$ coli in $24(11.2 \%)$, and Klebsiella spp in nine (4.2\%). Of the 3820 patients (311 cohort), 3644 (247 cohort) had no bacteraemias, 151 patients (48 cohort) had one episode, 15 (nine cohort) had two, eight (five cohort) had three, and single cohort children had four and five episodes.

AGE AND SEX

The age at infection (table 1) indicates that $68 \%$ of infections occurred before the age of 10 years and $80 \%$ before 20 years. There was no sex difference overall ( $53 \%$ boys $/ \mathrm{men} ; \chi^{2}=3.2$; $\mathrm{p}=0.07)$, although boys/men predominated among infections with haemophilus (risk ratio, $3.1 ; 95 \% \mathrm{CI}, 1.4$ to $7.0 ; \chi^{2}=8.4 ; \mathrm{p}<0.01$ ) and salmonella (risk ratio, $1.9 ; 95 \%$ CI, 1.2 to 3.1 ; $\chi^{2}=7.2 ; \mathrm{p}=0.01$ ), but not with $S$ pneumoniae (risk ratio, $1.0 ; 95 \% \mathrm{CI}, 0.6$ to $1.5 ; \chi^{2}=0$; $\mathrm{p}=0.99$ ) or klebsiella (risk ratio, $4.0 ; 95 \% \mathrm{CI}$, 0.8 to $\left.19.1 ; \chi^{2}=3.5 ; p=0.06\right)$. Infections with $E$ coli predominated among girls/women (risk ratio, $20.3 ; 95 \% \mathrm{CI}, 2.7$ to $150.3 ; \chi^{2}=17.6$; $\mathrm{p}<0.001)$.

Table 2 Age related incidence of infections among 311 patients in the cohort group and 3509 patients in the main study patients given as standardised infections rates (SIR)

\begin{tabular}{|c|c|c|c|c|c|}
\hline & \multicolumn{5}{|c|}{ Age group (years) } \\
\hline & $0-2$ & $3-5$ & $6-9$ & $10-19$ & $20+$ \\
\hline \multicolumn{6}{|l|}{ Cohort group } \\
\hline Events & 30 & 26 & 17 & 13 & 4 \\
\hline Patient-years $\times 1000$ & 0.87 & 0.81 & 1.01 & 1.94 & 0.24 \\
\hline Rate & 34.5 & 32.1 & 16.9 & 6.7 & 17.0 \\
\hline $95 \% \mathrm{CI}$ & (23.1 to 53.9 ) & (20.9 to 51.8$)$ & (10.5 to 29.0$)$ & (3.7 to 13.5 ) & (6.6 to 57.8$)$ \\
\hline SIR & 1.9 & 1.7 & 0.9 & 0.4 & 0.9 \\
\hline $95 \% \mathrm{CI}$ & (1.3 to 2.9 ) & (1.1 to 2.8$)$ & (0.6 to 1.6$)$ & $(0.2$ to 0.7$)$ & (0.4 to 3.1$)$ \\
\hline \multicolumn{6}{|l|}{ Main group } \\
\hline Events & 21 & 30 & 21 & 13 & 39 \\
\hline Patient-years $\times 1000$ & 1.07 & 2.31 & 3.53 & 9.69 & 16.62 \\
\hline Rate & 19.6 & 13.0 & 6.0 & 1.3 & 2.4 \\
\hline $95 \% \mathrm{CI}$ & (11.9 to 34.7 ) & (8.8 to 20.0$)$ & (3.9 to 9.6 ) & (0.8 to 2.5$)$ & (1.7 to 3.3 ) \\
\hline SIR & 5.3 & 3.5 & 1.6 & 0.4 & 0.6 \\
\hline $95 \% \mathrm{CI}$ & (3.2 to 9.4 ) & (2.4 to 5.4 ) & (1.1 to 2.6$)$ & $(0.02$ to 0.7$)$ & $(0.5$ to 0.9$)$ \\
\hline \multicolumn{6}{|l|}{ Both patient groups } \\
\hline Events & 51 & 56 & 38 & 26 & 43 \\
\hline Patient-years $\times 1000$ & 1.94 & 3.12 & 4.54 & 11.63 & 16.85 \\
\hline Rate & 26.3 & 17.9 & 8.4 & 2.2 & 2.6 \\
\hline $95 \% \mathrm{CI}$ & (19.2 to 36.9 ) & (13.4 to 24.5$)$ & (6.1 to 11.9$)$ & (1.5 to 3.5$)$ & (1.9 to 3.5$)$ \\
\hline SIR & 4.7 & 3.2 & 1.5 & 0.4 & 0.5 \\
\hline $95 \%$ CI & (3.4 to 6.6 ) & (2.4 to 5.4 ) & (1.1 to 2.1 ) & (0.3 to 0.6$)$ & (0.3 to 0.6 ) \\
\hline
\end{tabular}

CI, confidence intervals. 
Table 3 Secular pattern showing incidence rates for the two most common bacteraemias

\begin{tabular}{|c|c|c|c|c|}
\hline & $1974-79$ & $1980-85$ & $1986-91$ & $1992-97$ \\
\hline \multicolumn{5}{|l|}{ Streptococcus pneumoniae } \\
\hline \multicolumn{5}{|l|}{ Main group } \\
\hline Events & 5 & 13 & 8 & 16 \\
\hline Patient-years $\times 1000$ & 5.2 & 7.8 & 10.0 & 10.3 \\
\hline Incidence & 1.0 & 1.7 & 0.8 & 1.6 \\
\hline $95 \% \mathrm{CI}$ & (0.4 to 2.9$)$ & $(0.8$ to 4.2$)$ & (0.4 to 1.8$)$ & (1.0 to 2.7 ) \\
\hline \multicolumn{5}{|l|}{ Cohort group } \\
\hline Events & 14 & 17 & 4 & 4 \\
\hline Patient-years $\times 1000$ & 0.7 & 1.5 & 1.4 & 1.2 \\
\hline Incidence & 19.9 & 11.5 & 2.9 & 3.5 \\
\hline $95 \%$ CI & (9.5 to 48.8 ) & (6.9 to 20.4 ) & $(1.1$ to 10.2$)$ & (1.3 to 12.3$)$ \\
\hline \multicolumn{5}{|l|}{ Salmonella spp } \\
\hline \multicolumn{5}{|l|}{ Main group } \\
\hline Events & 0 & 3 & 13 & 27 \\
\hline Patient-years $\times 1000$ & 5.2 & 7.8 & 10.0 & 10.3 \\
\hline Incidence & 0.0 & 0.4 & 1.3 & 2.6 \\
\hline $95 \%$ CI & - & $(0.1$ to 1.9$)$ & (0.8 to 2.4$)$ & (1.8 to 3.9$)$ \\
\hline \multicolumn{5}{|l|}{ Cohort group } \\
\hline Events & 6 & 11 & 8 & 2 \\
\hline Patient-years $\times 1000$ & 0.7 & 1.5 & 1.4 & 1.2 \\
\hline Incidence & 8.5 & 7.4 & 5.7 & 1.7 \\
\hline $95 \% \mathrm{CI}$ & (3.9 to 22.2 ) & (4.2 to 14.3 ) & (3.0 to 12.7 ) & (0.4 to 17.2$)$ \\
\hline
\end{tabular}

CI, confidence intervals.

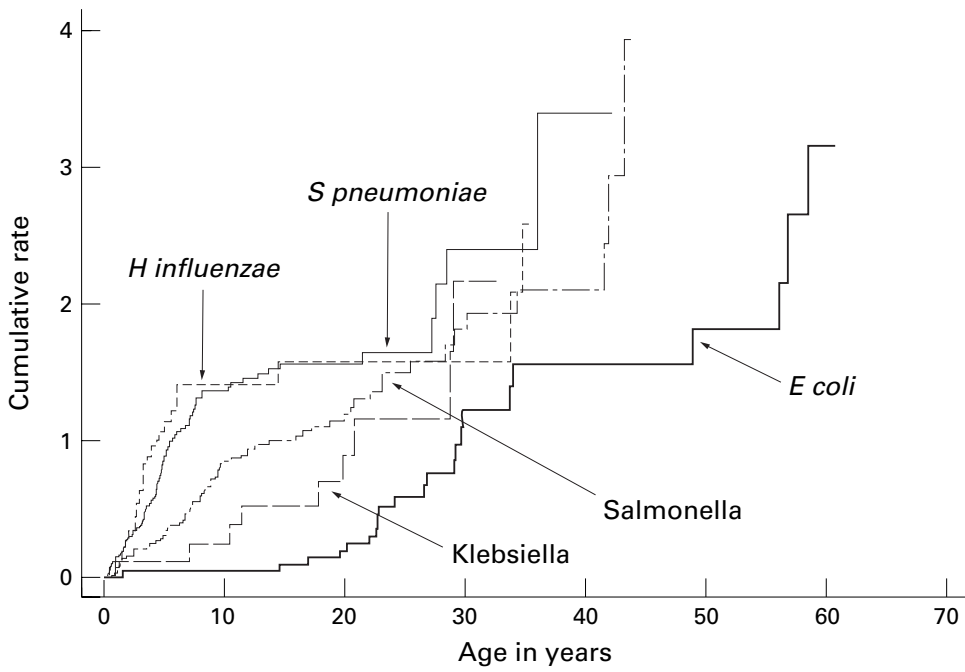

Figure 1 Cumulative incidence rate of five bacteraemias in relation to age among 214 bacteraemic episodes.

Table 4 Standardised infection rates (95\% CI) for the three most common infections relative to the whole sickle cell population

\begin{tabular}{llll}
\hline \multirow{2}{*}{ Organism } & \multicolumn{2}{l}{ Age group (years) } & \multicolumn{2}{l}{$6-9$} \\
\cline { 2 - 4 } & $0-2$ & $3-5$ & $0.6(0.1$ to 5.6$)$ \\
Haemophilus influenzae type b & $9.2(5.3$ to 17.1$)$ & $4.5(2.5$ to 8.7$)$ & $1.3(0.8$ to 2.5$)$ \\
Streptococcus pneumoniae & $5.3(3.4$ to 8.9$)$ & $5.1(3.4$ to 17.9$)$ & $1.3 .6(1.8$ to 4.1$)$ \\
Salmonella spp & $3.6(2.2$ to 6.6$)$ & $1.7(0.9$ to 3.8$)$ & 2.6 \\
\hline
\end{tabular}

CI, confidence intervals.

INCIDENCE

Crude incidence for all bacteraemias was 5.6/1000 patient-years (95\% CI, 4.8 to 6.6 ), with cohort patients showing a fivefold greater frequency than patients in the main group (18.5/1000 patient-years (95\% CI, 15.1 to 22.8) v 3.7/1000 patient-years (95\% CI, 3.1 to 4.5)). This difference will have been exaggerated by the predominance of older subjects, less prone to bacteraemia, in the main group of patients. When this difference was allowed for by comparing relative incidence within age bands (table 2), the risk ratio for bacteraemia among cohort relative to main group patients fell to $2.6(95 \% \mathrm{CI}, 1.9$ to 3.5$)$. In individual age bands, the risk ratios for the cohort group relative to the main group were as follows: ages 0-2 years, 1.8 (95\% CI, 1.0 to 3.1 ); ages $3-5$ years, 2.5 (95\% CI, 1.5, 4.2); ages, $6-9$ years, 2.8 (95\% CI, 1.5 to 5.4 ); ages $10-19$ years, 5.0 (95\% CI, 2.3 to 10.8 ); and age 20 years and above, 7.2 (95\% CI, 2.6 to 20.3). Incidence decreased linearly with age both in patients in the cohort group $\left(\chi^{2}=21.6 ; \mathrm{p}<0.001\right)$ and the main study group $\left(\chi^{2}=61.6 ; \mathrm{p}<0.001\right)$. Incidence rates for the five bacteraemias were consistently higher in the cohort group than the main study group: pneumococcus, $8.0 v$ 1.3; salmonella, $5.6 v$ 1.3; haemophilus, $2.7 v$ $0.5 ; E$ coli, 1.2 v 0.5; and klebsiella, $1.0 \vee 0.1$, respectively.

\section{SECULAR TRENDS}

The introduction of penicillin prophylaxis in the middle of the 1980s might have been expected to modify incidence rates; therefore, a secular analysis was performed for the two most common bacteraemias (table 3). The incidence of pneumococcal infection declined significantly among patients in the cohort group $\left(\chi^{2}=19.1 ; \mathrm{p}<0.001\right)$, and this trend was most marked between 1980 and 1985 and 1986 and 1991. However, this apparent secular change could be an artefact from the age structure of the cohort group, which meant that by 1986 few subjects remained in the high risk age group. Adjusting for age by stratifying into two age groups $(0-5$ years, $\geqslant 6$ years) showed a smaller, non-significant decline $\left(\chi^{2}=0.8\right.$; $\mathrm{p}=0.38)$. No secular change occurred within patients from the main clinic, either before or after stratification. For Salmonella spp, the incidence did not change over time for patients in the cohort group, either before $\left(\chi^{2}=2.8\right.$; $\mathrm{p}=0.10)$ or after controlling for age $\left(\chi^{2}=1.3\right.$; $\mathrm{p}=0.25$ ), but among patients in the main group, the incidence of infection increased significantly with time $\left(\chi^{2}=16.8 ; p<0.001\right)$, and this persisted after controlling for age $\left(\chi^{2}=17.0 ; \mathrm{p}<0.001\right)$.

CUMULATIVE INCIDENCE

In the whole group, cumulative incidence rose sharply to 10 years of age and then at a lower rate. Different cumulative incidence rates occurred with the different organisms (fig 1), $H$ influenzae and $S$ pneumoniae occurring predominantly before 5 years of age, although salmonella showed no age predilection and increased linearly with age. Standardised infection rates (table 4) confirm the different age patterns for the three most common organisms. The small numbers of both $E$ coli and Klebsiella spp occurred predominantly in those aged over 20 years.

RECURRENT INFECTION

The different epidemiology of $E$ coli infections (later age, confined mainly to girls/women) implies different risk factors; therefore, this organism was excluded from the analysis of recurrent bacteraemia. The probability of subsequent infection after an initial bacteraemic episode, assessed by standardised infection rates, was $4.8(95 \% \mathrm{CI}, 3.2$ to 7.4$)$ times greater, and among those with two previous 
Table 5 Patients with three or more infections

\begin{tabular}{|c|c|c|c|}
\hline \multicolumn{2}{|c|}{ Patient number and organism } & Source & Age (years) \\
\hline \multicolumn{4}{|c|}{ Cohort group } \\
\hline \multirow[t]{4}{*}{1} & Salmonella schwartzendgrund & Pus & 1.3 \\
\hline & Haemophilus influenzae type b & Blood & 3.6 \\
\hline & Salmonella heidelberg & Blood & 10.6 \\
\hline & Salmonella montevideo & Blood & 17.2 (died) \\
\hline \multirow[t]{5}{*}{2} & Streptococcus pneumoniae type 23 & Blood & 2.4 \\
\hline & Haemophilus influenzae type $\mathrm{b}$ & Blood & 2.7 \\
\hline & Streptococcus pneumoniae type? & Blood & 3.6 \\
\hline & Streptococcus pneumoniae type? & Blood & 3.7 \\
\hline & Streptococcus pneumoniae type 23 & Blood & 4.8 \\
\hline \multirow[t]{3}{*}{3} & Haemophilus influenzae type $\mathrm{b}$ & Blood & 2.0 \\
\hline & Streptococcus pneumoniae type? & Blood/CSF & 4.3 \\
\hline & Streptococcus pneumoniae type? & Blood/CSF & 7.3 (died) \\
\hline \multirow[t]{3}{*}{4} & Salmonella montevideo & Pus & 3.8 \\
\hline & Salmonella montevideo & Blood & 5.2 \\
\hline & Streptococcus pneumoniae type 6 & Blood & 7.7 \\
\hline \multirow[t]{3}{*}{5} & Haemophilus influenzae type b & Blood & 0.8 \\
\hline & Haemophilus influenzae type $\mathrm{b}$ & Blood & 1.6 \\
\hline & Streptococcus pneumoniae type 23 & Blood & 1.8 (died) \\
\hline \multirow[t]{3}{*}{6} & Streptococcus pneumoniae type 23 & Blood & 3.8 \\
\hline & Streptococcus pneumoniae type? & Blood & 5.8 \\
\hline & Streptococcus pneumoniae type 23 & Blood & 19.7 (died) \\
\hline \multicolumn{4}{|c|}{ Main group } \\
\hline \multirow[t]{3}{*}{7} & Streptococcus pneumoniae type 23 & Blood & 4.5 \\
\hline & Streptococcus pneumoniae type 23 & Blood & 4.6 \\
\hline & Streptococcus pneumoniae type 23 & Blood & 4.8 \\
\hline \multirow[t]{3}{*}{8} & Streptococcus pneumoniae type 6 & CSF & 1.8 \\
\hline & Salmonella enteritidis & Blood & 13.7 \\
\hline & Salmonella heidelberg & Blood & 23.1 \\
\hline \multirow[t]{3}{*}{9} & Streptococcus pneumoniae type? & CSF & 0.5 \\
\hline & Salmonella spp & Blood & 1.3 \\
\hline & Streptococcus pneumoniae type? & Blood & 1.8 \\
\hline
\end{tabular}

CSF, cerebrospinal fluid. ardised infection rates for $S$ pneumoniae and $H$ influenzae fell sharply after 5 years of age, whereas that for salmonella remained relatively constant, giving an almost linear cumulative incidence rate. The declining prevalence of bacteraemias after the age of 5 years is consistent with previous reports, ${ }^{9-11}$ and implies a role of actively acquired immunity, although pneumococcal prophylaxis may also have contributed.

A secular analysis adjusting for age did not confirm an expected fall in pneumococcal bacteraemias in the middle of the 1980s consistent with effective prophylaxis, which was surprising. The incidence of salmonella, on the other hand, did not change in the cohort group but increased significantly in the main group of patients, indicating a real and not just a relative increase in Salmonella spp isolations. This reflects the greater importance of salmonella in Jamaica ${ }^{3}$ : this organism was the most common one to be isolated after 6 years of age.

Substantial differences were apparent between the cohort and main patient groups. The age structure of these groups differed, the oldest subjects being 24.5 years in the cohort group compared with 80.6 in the main group. Although the interquartile ranges were less disparate (cohort group, 11.2-21.2; main group, 10.7-31.4), this difference in age distribution affected the pattern of infection, because 19 of 38 bacteraemias in patients in the main group aged 20 years and above were caused by $E$ coli compared with two of six in the cohort group. However, although it complicated assessment of the data, the inclusion of patients from the main group contributed most of the events, thereby increasing the sensitivity of analysis. The unadjusted fivefold increase in infections among patients in the cohort group (18.5/1000 patient-years) compared with main clinic patients (3.7/1000 patient-years) was also a concern, raising the possibility of considerable underdiagnosis in patients in the main group, but analysis of incidence within narrower age bands reduced this relative incidence to 2.6-fold. Factors contributing to this difference included the more comprehensive and complete follow up of the cohort group and the fact that patients in the main study group are more likely than those in the cohort group to attend other health care institutions, which might not have the same access to microbiological facilities. Under such circumstances, patients would be treated empirically, without culture confirmation of diagnosis. The cohort group who have been monitored closely in this clinic since birth, would almost certainly attend for illness and be investigated aggressively. Because care of sickle cell patients worldwide more closely resembles that in our main clinic group, the implications are that bacteraemia is underdiagnosed.

The clinical impression that a subgroup of patients with SS may be prone to recurrent infection was supported by our data, which showed that the risks of second and third infections were 4.8 and 15.8 times greater, respectively, than the SS population average. The most common pattern was recurrent 
pneumococcal bacteraemia, which occurred in six of 14 patients with two bacteraemias and in five of nine patients with three or more bacteraemias. The next most common was the occurrence of pneumococcal and salmonellae bacteraemias in five and three of the two groups, respectively, and haemophilus bacteraemia, which occurred with other bacteraemias in three and four of the two groups, respectively. This extreme susceptibility is also demonstrated by patient number 1 of the cohort group (table 5), who harboured three different strains of salmonella over 16 years and also had a haemophilus bacteraemia. The importance of these observations are threefold. First, these patients represent a subgroup of patients with SS who are particularly prone to bacteraemia, and in whom the mechanism of such susceptibility should be investigated. The possible importance of the early loss of splenic function is supported by data from eastern Saudi Arabia, in which high concentrations of fetal haemoglobin are associated with persisting splenic function ${ }^{12} 13$ and a lower incidence of bacteraemia. Second, there are implications for management because the greater risk of bacteraemia in patients who have already had one or two events should lead to aggressive investigation and management. Third, the greater increase in the bacterial isolation rate in patients monitored closely in the cohort group implies that many bacteraemias may pass undiagnosed in ordinary clinical practice.

1 Barrett-Connor E. Bacterial infection and sickle cell anemia. Medicine 1971;50:97-112.

2 Powars D, Overturf G, Turner E. Is there an increased risk of Haemophilus influenzae septicemia in children with sickle cell anemia? Pediatrics 1983;71:927-31.

3 Wright J, Thomas P, Serjeant GR. Septicemia caused by salmonella infection: an overlooked complication of sickle cell disease. F Pediatr 1997;130:394-9.

4 Pearson HA, McIntosh S, Ritchey AK, Lobel JS, Rooks Y, Johnston D. Developmental aspect of splenic function in Johnston D. Developmental aspect of sp.
sickle cell disease. Blood 1979;53:358-65.

5 Rogers DW, Vaidya S, Serjeant GR. Early splenomegaly in homozygous sickle cell disease: an indicator of susceptibility. Lancet 1978;2:963-5.

6 Serjeant GR. Diagnosis of sickle cell disease. In: Sickle cell disease, 2nd ed. Oxford: Oxford University Press, 1992:3953.

7 Efron B, Tibshirani RJ. The jacknife. An introduction to the bootstrap. New York: Chapman and Hall, 1993:141-52.

8 Clayton D, Hills M. Rates. Statistical models in epidemiology. Oxford: Oxford University Press, 1993:40-52.

9 Zarkowsky HS, Gallagher D, Gill FM, et al. Bacteremia in sickle hemoglobinopathies. F Pediatr 1986;109:579-85.

10 Overturf GD, Powars D, Baraff LJ. Bacterial meningitis and septicemia in sickle cell disease. Am F Dis Child 1977;131: septicemia 784 .

11 Lobel JS, Bove KE. Clinicopathologic characteristics of septicemia in sickle cell disease. Am 7 Dis Child 1982;136:5437 .

12 Al-Awamy B, Wilson WA, Pearson HA. Splenic function in sickle cell disease in the eastern province of Saudi Arabia. $\mathcal{F}$ Pediatr 1984;104:714-17.

13 Mallouh AA, Burke GM, Salamah M, Ahmad MS. Splenic function in Saudi children with sickle cell disease. Ann Trop Paediatr 1984;4:87-91. 